\title{
Research Paper: The Relationship Between Physical Activity, Lipid Profile, and Two New Anthropometric Cardiovascular Risk Factors Among Men
}

\author{
Mojtaba Amirabadizadeh $^{1^{*}}$ (D, Mohammad Esmaeil Afzalpour ${ }^{1}$ (D), Tooba Kazemi² \\ 1. Department of Sport Sciences, Faculty of Sport Sciences, University of Birjand, Birjand, Iran. \\ 2. Cardiovascular Diseases Research Center, Birjand University of Medical Sciences, Birjand, Iran.
}

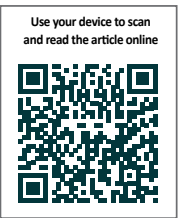

Ctration Amirabadizadeh M, Afzalpour ME, Kazemi T. The Relationship Between Physical Activity, Lipid Profile, and Two New Anthropometric Cardiovascular Risk Factors Among Men. Journal of Research \& Health. 2020; 10(4):233-238. http:// dx.doi.org/10.32598/JRH.10.4.1434.1

http://dx.doi.org/10.32598/JRH.10.4.1434.1

\section{Keywords:}

Physical activity, Lipid profile, Cardiovascular disease, Risk factors, Anthropometric factors, Male

\begin{abstract}
Background: Cardiovascular diseases are among the most prevalent causes of morbidity and mortality. This research investigated the relationship between physical activity, lipid profile, and new anthropometric cardiovascular risk factors among men.

Methods: This cross-sectional study was conducted on 155 adult men (30-50 years old) who were selected randomly from 250 men called by public announcement. Standard methods were used to measure their anthropometric indices and then they were asked to complete the Baecke questionnaire. ANOVA was used to compare basic anthropometric and clinical characteristics in different age groups followed by Tukey's posthoc test. A correlation of anthropometric measurements with glucose and lipid parameters was determined by the Pearson correlation coefficient. $\mathrm{P}<0.05$ was considered as a significant level.

Results: The Mean $\pm \mathrm{SD}$ age of the participants was $39.8 \pm 0.5$ years. Their Mean $\pm \mathrm{SD}$ Body Mass Index (BMI) was $25.6 \pm 0.3 \mathrm{~kg} / \mathrm{m}^{2}$ with a Mean \pm SD Neck Circumference (NC) of $38.4 \pm 0.1 \mathrm{~cm}$, and Mean \pm SD Wrist Circumference (WRC) of $17.4 \pm 0.0 \mathrm{~cm}$. There was a statistically significant difference between age groups concerning height, BMI, WRC, and Fasting Blood Glucose (FBG). The $\mathrm{NC}$ showed statistically significant correlation with weight $(\mathrm{r}=0.7, \mathrm{P}<0.001)$, triglyceride $(\mathrm{r}=0.1, \mathrm{P}=0.033)$, High-Density Lipoprotein $(\mathrm{HDL})(\mathrm{r}=-0.2, \mathrm{P}=0.007)$ and Physical Activity (PA) $(\mathrm{r}=-0.1, \mathrm{P}=0.020)$. Also the WRC had statistically significant correlation with weight $(\mathrm{r}=0.7, \mathrm{P}<0.001)$, height $(\mathrm{r}=0.1, \mathrm{P}=0.021)$ and $\mathrm{HDL}(\mathrm{r}=-0.1, \mathrm{P}=0.024)$.

Conclusion: Measuring NC like other methods was a potential assessment tool of cardiovascular risk factors and can be used for epidemiological studies. Also, WRC had no significant relation. However, WRC's negative correlation with HDL was very important and can indicate the health
\end{abstract} status of individuals.

\footnotetext{
* Corresponding Author:

Mojtaba Amirabadizadeh, MSc.

Address: Department of Sport Sciences, Faculty of Sport Sciences, University of Birjand, Birjand, Iran.

Phone: +98 (938) 7244387

E-mail:m.amirabadi@birjand.ac.ir
} 


\section{Introduction}

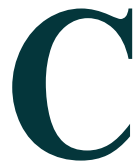

ardiovascular diseases are among the most common causes of morbidity and mortality around the world. Inactivity, unhealthy diet, smoking, high-risk lifestyle, obesity, etc., can be the major risk factors for cardiovascular diseases [1]. Measuring Body Mass Index (BMI) and obesity are common and comprehensive approaches to evaluate and screen the health of the population. Therefore, several methods have been developed to measure body fat. However, laboratory methods are often costly and time-consuming and require advanced equipment and experiences [2].

Waist Circumference (WC), Waist-Hip Ratio (WHR), and BMI are low-cost evaluation factors that are related to dyslipidemia as cardiovascular risk factors [3-5]. Studies indicate that cardiovascular disease risk factors are dyslipidemia (75\%), overweight and obesity (53\%), and hypertension $(16.5 \%)[6,7]$. Also, one of the most important risk factors for cardiovascular diseases is dyslipidemia. It can be determined by other indices such as high levels of cholesterol, triglyceride, and Low-Density Lipoprotein (LDL) and low level of High-Density Lipoprotein (HDL) [7].

Circumferences of neck and wrist are considered as anthropometric indices in addition to WC, WHR, and BMI [8-12]. Many studies have been performed to investigate an accurate relationship between these two indices and cardiovascular disease risk factors [13]. Ben-Noun et al. demonstrated that the circumference of the neck can be used to predict cardiovascular risk factors [14]. Moreover, Tatar et al. reported that neck and wrist circumferences are reliable indicators to predict the metabolic syndrome and cardiovascular diseases [10]. Other studies revealed that wrist circumference is an appropriate predictor for cardiovascular disease $[9,11,15]$.

It is necessary to evaluate the relationship between new indices and physical activity levels to have a better understanding of new anthropometric indices (neck and wrist circumferences) because few studies have been done in this regard. Tibana et al. showed that physical exercise can be effective in preventing cardiovascular diseases by improving the neck muscle strength [12]. This research aimed to investigate the relationship between physical activity, lipid profile, and two new anthropometric cardiovascular risk factors among men.

\section{Methods}

This cross-sectional study was conducted on men (3050 years old) in Birjand City, Iran. In one of the clinics in Birjand, 151 men (out of 250 participants) were volunteered for participation in this study. Based on the exclusion criteria, 4 people excluded because of their physical disabilities in the wrist (1 person), in the waist and hips ( 2 people), and neck (1 person). After choosing the samples, permission and written consent were obtained from them. The subjects were asked to complete the Baecke Questionnaire for physical activity [16]. It has three parts: the level of physical activity at work, the level of individual sports activities, and leisure activity. Questions were rated on a 5-point Likert-type scale and physical activity score was obtained by calculation of these three-part scores. Standard methods were used to measure the anthropometric indices. Height and weight were measured by weighing scale and measuring tape, respectively and then BMI was calculated by dividing weight $(\mathrm{kg})$ over squared height $\left(\mathrm{m}^{2}\right)$.

Circumference of the widest part of the hip (WH) was evaluated while the samples were standing on a smooth and flat place. Waist circumference was measured while the samples were standing without clothes and the tape measure was placed between the last rib and the iliac crest. Neck circumference was measured while the samples were standing erect with their head positioning in Frankfort horizontal level and the tape measure was placed right under laryngeal prominence [10, 12, 17]. Wrist circumference was measured with subjects in a seated position using tape measuring right and left wrists. Twelve hours of fasting blood samples were taken by skilled technicians.

The samples were transported to the lab immediately and stored in a freezer at $-10^{\circ} \mathrm{C}$. The level of Total Cholesterol (TC), Triglycerides (TG), Low-Density Lipoprotein (LDL), High-Density Lipoprotein (HDL), and Fasting Blood Glucose (FBG) were measured by using the enzymatic colorimetric method [18]. Dyslipidemia was defined as the presence of at least one criteria such as high cholesterol $(>240)$ or non-HDL-C $(>160)$ or high TG $(>200)$ or high LDL $(>130)$ or low HDL ( $<40$ for men) [19].

The test results and medical recommendations were given to the participants and after surveying the information and ensuring that they were correctly entered into SPSS V. 22. Descriptive information was presented by using mean and standard error. The normality test was performed by the Kolmogorov-Smirnov test. Levene's test was performed to evaluate the homogeneity 
of variances. ANOVA was used to compare basic anthropometric and clinical characteristics in different age groups followed by Tukey's post-hoc test. A correlation of anthropometric measurements with glucose and lipid parameters was evaluated by the Pearson correlation coefficient. $\mathrm{P}<0.05$ was considered as a significant level.

\section{Results}

The results showed that the Mean $\pm \mathrm{SD}$ age of all men was $39.8 \pm 0.5$ years. Their Mean \pm SD BMI was $25.6 \pm 0.3$ $\mathrm{kg} / \mathrm{m}^{2}$ with a Mean \pm SD waist circumference of $95.5 \pm 0.9$ $\mathrm{cm}$. Also, their Mean \pm SD HC was $102.3 \pm 0.6 \mathrm{~cm}$, WHR

Table 1. Basic anthropometric characteristics of participants

\begin{tabular}{|c|c|c|c|c|c|c|}
\hline \multirow{3}{*}{ Parameters } & \multicolumn{4}{|c|}{ Mean $\pm S D$} & \multicolumn{2}{|c|}{ ANOVA } \\
\hline & \multicolumn{4}{|c|}{ Age Group (Y) } & \multirow{2}{*}{ Statistics } & \multirow{2}{*}{$\mathbf{P}$} \\
\hline & $30-35$ & $35-40$ & $40-45$ & $45-50$ & & \\
\hline Weight (kg) & $77.9 \pm 1.8$ & $81.8 \pm 2.0$ & $79.9 \pm 2.1$ & $80.8 \pm 2.2$ & 0.5 & 0.702 \\
\hline Height (cm) & $180.3 \pm 0.9$ & $178.7 \pm 0.8$ & $174.5 \pm 1.3^{\mathrm{ab}}$ & $173.4 \pm 0.9^{\mathrm{abc}}$ & 9.1 & $<0.001^{*}$ \\
\hline BMI $\left(\mathrm{kg} / \mathrm{m}^{2}\right)$ & $24.1 \pm 0.6$ & $25.5 \pm 0.5$ & $26.2 \pm 0.7$ & $27.1 \pm 0.7^{a}$ & 2.7 & $0.014 *$ \\
\hline$W C(\mathrm{~cm})$ & $91.7 \pm 1.6$ & $97.1 \pm 1.6$ & $98.7 \pm 1.6^{a}$ & $99.6 \pm 1.8^{\mathrm{a}}$ & 3.2 & $0.006 *$ \\
\hline $\mathrm{HC}(\mathrm{cm})$ & $100.0 \pm 1.0$ & $102.9 \pm 1.2$ & $103.1 \pm 1.2$ & $103.0 \pm 1.3$ & 0.6 & 0.624 \\
\hline $\mathrm{NC}(\mathrm{cm})$ & $38.0 \pm 0.3$ & $38.6 \pm 0.3$ & $38.3 \pm 0.2$ & $38.7 \pm 0.4$ & 0.8 & 0.497 \\
\hline WRC $(\mathrm{cm})$ & $17.2 \pm 0.1$ & $17.4 \pm 0.1$ & $17.5 \pm 0.1$ & $17.7 \pm 0.1$ & 1.8 & 0.100 \\
\hline PA & $7.0 \pm 0.1$ & $7.0 \pm 0.1$ & $1.0 \pm 0.3$ & $7.2 \pm 0.1$ & 0.5 & 0.675 \\
\hline
\end{tabular}

BMI: Body Mass Index; WC: Waist Circumference; HC: Hip Circumference; NC: Neck Circumference; WRC: Wrist Circumference; PA: Physical Activity;

a Significant difference with age 30-35; b Significant difference with age 35-40; c Significant difference with 40-45.

$* \mathrm{P}<0.05$

Table 2. Basic clinical characteristics of participants

\begin{tabular}{|c|c|c|c|c|c|c|}
\hline \multirow{3}{*}{ Parameters } & \multicolumn{4}{|c|}{ Mean士SD } & \multirow{2}{*}{\multicolumn{2}{|c|}{ ANOVA }} \\
\hline & \multicolumn{4}{|c|}{ Age Group (Y) } & & \\
\hline & $30-35$ & $35-40$ & $40-45$ & $45-50$ & Statistic & $\mathbf{P}$ \\
\hline FBG (mg/dL) & $85.5 \pm 1.5$ & $86.6 \pm 1.6$ & $86.8 \pm 2.1$ & $105.5 \pm 5.7^{a}$ & 7.0 & $<0.001 *$ \\
\hline $\mathrm{TC}(\mathrm{mg} / \mathrm{dL})$ & $194.3 \pm 5.2$ & $193.6 \pm 5.5$ & $215.5 \pm 8.0$ & $207.1 \pm 6.5$ & 2.4 & 0.087 \\
\hline $\mathrm{LDL}(\mathrm{mg} / \mathrm{dL})$ & $119.8 \pm 4.3$ & $125.1 \pm 5.0$ & $137.7 \pm 6.4$ & $131.1 \pm 5.0$ & 2.1 & 0.077 \\
\hline $\mathrm{HDL}(\mathrm{mg} / \mathrm{dL})$ & $39.8 \pm 0.9$ & $41.6 \pm 1.1$ & $43.6 \pm 1.4$ & $41.0 \pm 1.2$ & 1.2 & 0.312 \\
\hline $\mathrm{TG}(\mathrm{mg} / \mathrm{dL})$ & $182.2 \pm 18.4$ & $135.5 \pm 9.9$ & $167.4 \pm 19.8$ & $192.8 \pm 40.3$ & 0.9 & 0.442 \\
\hline
\end{tabular}

MRA

PA: Physical Activity; FBG: Fasting Blood Glucose; TC: Total Cholesterol; TG: Total Triglycerides; LDL: Low-Density Lipoprotein; HDL: High-Density Lipoprotein;

a Significant difference with age 30-35; b Significant difference with age 35-40; c Significant difference with 40-45

${ }^{*} \mathrm{P}<0.05$. 
Table 3. The correlations of anthropometric measurements with glucose and lipid parameters

\begin{tabular}{|c|c|c|c|c|c|c|c|}
\hline Parameters & & BMI & WC & $\mathrm{HC}$ & NC & WRC & WHR \\
\hline \multirow[b]{2}{*}{ Weight } & $\mathrm{R}$ & 0.8 & 0.9 & 0.8 & 0.7 & 0.7 & 0.6 \\
\hline & $P$ & $<0.001^{*}$ & $<0.001^{*}$ & $<0.001 *$ & $<0.001 *$ & $<0.001 *$ & $<0.001 *$ \\
\hline \multirow{2}{*}{ Height } & $\mathrm{R}$ & -0.2 & -0.08 & 0.03 & -0.01 & 0.1 & -0.2 \\
\hline & $P$ & $0.003^{*}$ & 0.300 & 0.681 & 0.814 & $0.021^{*}$ & $0.006^{*}$ \\
\hline \multirow{2}{*}{ FBG } & $\mathrm{R}$ & 0.1 & 0.05 & -0.01 & 0.1 & 0.04 & 0.1 \\
\hline & $P$ & 0.226 & 0.483 & 0.826 & 0.247 & 0.572 & 0.999 \\
\hline \multirow{2}{*}{ TC } & $\mathrm{R}$ & 0.1 & 0.1 & 0.08 & 0.07 & 0.08 & 0.1 \\
\hline & $P$ & 0.095 & 0.106 & 0.292 & 0.340 & 0.337 & 0.110 \\
\hline \multirow{2}{*}{ TG } & $\mathrm{R}$ & 0.1 & 0.1 & 0.1 & 0.1 & 0.1 & 0.1 \\
\hline & $P$ & 0.070 & 0.089 & 0.227 & $0.033^{*}$ & 0.064 & 0.062 \\
\hline \multirow{2}{*}{ LDL } & $\mathrm{R}$ & 0.03 & 0.01 & -0.01 & -0.004 & 0.003 & 0.036 \\
\hline & $P$ & 0.691 & 0.843 & 0.853 & 0.957 & 0.968 & 0.663 \\
\hline \multirow{2}{*}{$\mathrm{HDL}$} & $\mathrm{R}$ & -0.04 & -0.08 & -0.06 & -0.2 & -0.1 & -0.1 \\
\hline & $\mathrm{P}$ & 0.622 & 0.303 & 0.432 & $0.007 *$ & $0.024 *$ & 0.159 \\
\hline \multirow{2}{*}{ Non-HDL-C } & $\mathrm{R}$ & 0.1 & 0.1 & 0.1 & 0.1 & 0.1 & 0.1 \\
\hline & P & 0.061 & 0.055 & 0.202 & 0.120 & 0.141 & $0.047^{*}$ \\
\hline \multirow{2}{*}{ PA } & $\mathrm{R}$ & -0.1 & -0.2 & -0.2 & -0.1 & -0.1 & -0.1 \\
\hline & P & 0.115 & $0.019 *$ & $0.020^{*}$ & $0.020^{*}$ & 0.234 & 0.073 \\
\hline
\end{tabular}

IPAP

BMI: Body Mass Index; WC: Waist Circumference; HC: Hip Circumference; WHR: Waist-Hip Ratio; NC: Neck Circumference; WRC: Wrist Circumference; PA: Physical Activity; FBG: Fasting Blood Glucose; TC: Total Cholesterol, TG: Total Triglycerides; LDL: Low-Density Lipoprotein; HDL: High-Density Lipoprotein

$* \mathrm{P}<0.05$.

$0.9 \pm 0.01 \mathrm{~cm}, \mathrm{NC} 38.4 \pm 0.1 \mathrm{~cm}$, and WRC $17.4 \pm 0.55 \mathrm{~cm}$. The demographic features of subjects and their comparisons between age groups can be seen in Table 1. There were statistically significant differences between age groups concerning height, BMI, and WC. Post-hoc analysis showed that older men had shorter height, higher $\mathrm{BMI}$, and WBC in comparison with young participants.

The Mean \pm SD FBG level of all men was $90.7 \pm 1.6$, TC was $200 \pm 3.1$, LDL was $126.9 \pm 2.5$, HDL was $41.3 \pm 0.6$, and TG was $167.8 \pm 11.9$. There was a statistically significant increase in the mean FBG between older men and young participants (Table 2).
Table 3 shows that NC has statistically significant positive correlations with anthropometric and clinical parameters as weight $(\mathrm{r}=0.7, \mathrm{P}<0.001)$ and $\mathrm{TG}(\mathrm{r}=0.1$, $\mathrm{P}=0.033)$, negative correlation with $\mathrm{HDL}(\mathrm{r}=-0.2$, $\mathrm{P}=0.007)$ and Physical Activity (PA) $(\mathrm{r}=-0.1, \mathrm{P}=0.020)$. WRC also showed statistically significant positive correlation with weight $(\mathrm{r}=0.7, \mathrm{P}<0.001)$ and height $(\mathrm{r}=0.1$, $\mathrm{P}=0.021)$, and negative correlation with HDL $(\mathrm{r}=-0.1$, $\mathrm{P}=0.024)$. Also, physical activity showed a negative relationship with $\mathrm{WC}(\mathrm{r}=-0.2, \mathrm{P}=0.019), \mathrm{HC}(\mathrm{r}=-0.2$, $\mathrm{P}=0.020)$, and $\mathrm{NC}(\mathrm{r}=-0.1, \mathrm{P}=0.020)$. 


\section{Discussion}

To the best of our knowledge, the relationship between physical activity with two new indices (e.g. NC and WRC) has rarely been studied which makes it difficult to interpret the content and conclusions. Tibana et al. reported that risk factors of cardiovascular diseases can be reduced by the improvement of muscular strength of the neck [12]. Reduction in NC, indicating the more active the person is that is probably related to the regular exercise and increased energy expenditure, and regulation of hormonal activity. Also, enhanced cellular enzymes involved in fat breakdown leads to the use of intracellular TG in the process of energy production in aerobic activities. As a result, the release of free fatty acids into the bloodstream would reduce the size of fat cells around the neck.

Based on the results, the mean values of WRC, NC, and PA were not statistically different in age groups. However, WC and BMI increase by age statistically alike FBG and height. Samson et al. and Lernmark showed that by increasing age, the height would be reduced, and also FBG and BMI would increase [20, 21]. Correlation analysis showed that $\mathrm{NC}$ had positive correlations with anthropometric and clinical parameters like weight and TG which was similar to Ben-Noun et al. $[13,14,17]$ and Androutsos et al. [22] results. Also, a significant negative correlation between $\mathrm{NC}$ and HDL levels were found which was similar to Ben-Noun et al. [13] and Androutsos et al. [22] studies.

However, other research like Ben-Noun et al. indicated no significant relationship between HDL and NC [14, 17]. Moreover, LDL, TC, and non-HDL-C had no statistical relationship with $\mathrm{NC}$ which was similar to studies of Tatar et al. [10] and Androutsos et al [22]. Based on the results, an increase in $\mathrm{NC}$ could result from the accumulation of fat in the upper region of the body, an unhealthy condition for those with larger neck who should change their lifestyle, especially their diet and physical activity. Besides, a negative significant relationship between NC and PA indicated that physical activity could decrease $\mathrm{NC}$ as a cardiovascular risk factor.

WRC had a significant negative relationship with HDL, and no significant correlation with TC, TG, and LDL. Other studies have yielded different results $[10,11,15$, 23]. It can be stated that changes in the size of fat cells and the distribution of adipose tissue, can also cause changes in body composition [24]. Differences between the results of various studies may be due to differences in study populations. For example, some of the studies were conduct- ed on metabolic syndrome and cardiovascular patients while this study was conducted on a healthy population.

A high blood sugar level due to impaired insulin secretion is associated with a high intake of sugar. High consumption of sugar and high energy intake create extra calories stored as fat in adipose tissue. In this study, FBG had no significant relationship with any of the anthropometric indices such as NC or WRC. Patil et al. reported a positive association between FBG and anthropometric indices such as BMI, WHR, and WC [25]. Also, Tatar et al. [10] and BenNoun et al. [14] showed a significant positive correlation between NC and WRC with FBG level among women.

This study includes some limitations. The causal associations cannot be inferred by a cross-sectional study. Further research on more potential risk factors is needed to understand more comprehensively the use of new indices to develop prevention and control measures for epidemiological studies. Also, we did not control the nutritional status of the subjects.

\section{Conclusion}

The results showed that $\mathrm{NC}$ along with other traditional methods is a potential assessment tool for physical activity and cardiovascular risk factors and can be used in epidemiological studies. WRC has no significant relationship with these variables, especially physical activity. However, its negative correlation with HDL was very important and can indicate the health status of individuals potentially.

\section{Ethical Considerations}

\section{Compliance with ethical guidelines}

This study was approved by the Research Council Birjand University of Medical Sciences (Code:IR. BUMS.REC.1396.346).

\section{Funding}

The present paper was extracted from the MSc thesis of the first author Department of Sport Sciences, Faculty of Sport Sciences, University of Birjand.

\section{Authors' contributions}

Study design, data collection, and manuscript preparation: All authors; Data analysis: Mojtaba Amirabadizadeh; Mohammad Esmaeil Afzalpour. 


\section{Conflict of interest}

The authors declared no conflict of interest.

\section{References}

[1] Harald JS, Nele F, Jens K, Lars P, Matthias N, Ulrich J, et al. The predictive value of different measures of obesity for incident cardiovascular events and mortality. J Clin Endocrinol Metab. 2010; 95(4):1777-85. [DOI:10.1210/jc.2009-1584] [PMID]

[2] Chan RS, Woo J. Prevention of overweight and obesity: How effective is the current public health approach. Int J Environ Res Public Health. 2010; 7(3):765-83. [DOI:10.3390/ ijerph7030765] [PMID] [PMCID]

[3] Gharakhanlou R, Farzad B, Agha-Alinejad H, Steffen LM, Bayati M. Anthropometric measures as predictors of cardiovascular disease risk factors in the urban population of Iran Arq Bras Cardiol. 2012; 98(2):126-35. [DOI:10.1590/S0066782X2012005000007] [PMID]

[4] Kazemi T, Rezvani MR, Sharifzadeh GR, Sadri A, Mashraghi Moghaddam HR, Hosseinzadeh Maleki M. The prevalence of traditional cardiovascular risk factors in low socioeconomic use individuals in Birjand 2008 (East IRAN). J Cardio-Thorac Med. 2015; 3(1):263-9.

[5] Erem C, Hacihasanoglu A, Deger O, Kocak M, Topbas M. Prevalence of dyslipidemia and associated risk factors among Turkish adults: Trabzon lipid study. Endocr. 2008; 34(1-3):3651. [DOI:10.1007/s12020-008-9100-z] [PMID]

[6] Singh JA, Lu X, Ibrahim S, Cram P. Trends in and disparities for acute myocardial infarction: An analysis of medicare claims data from 1992-2010. BMC Med. 2014; 24)12(:190. [DOI:10.1186/s12916-014-0190-6] [PMID] [PMCID]

[7] Kazemi T, Nik M. "World heart day 2014", Significance of cardiovascular diseases in east of Iran. J Res Med Sci. 2015, 20(5):423. [DOI:10.4103/1735-1995.163950] [PMID] [PMCID]

[8] Mitrea A, Soare A, Popa SG, Tudor MN, Mota M, Pozzilli P. Wrist Circumference: An Independent Predictor of Both Insulin Resistance and Chronic Kidney Disease in an Elderly Population. Rom J Diabetes Nutr Metab Dis. 2013; 20(3):323-9. [DOI:10.2478/rjdnmd-2013-0031]

[9] Jahangiri Noudeh Y, Hadaegh F, Vatankhah N, Momenan AA, Saadat N, Khalili D, et al. Wrist circumference as a novel predictor of diabetes and prediabetes: Results of cross-sectional and 8.8-year follow-up studies. J Clin Endocrinol Metab. 2013; 98(2):777-84. [DOI:10.1210/jc.2012-2416] [PMID]

[10] Tatar BT, Ersoy C, Kacan T, Kirhan E, Sarandol E, Sigirli $\mathrm{D}$, et al. Neck and wrist circumferences propose a reliable approach to qualify obesity and insulin resistance. Med Sci. 2014; 3(1):1013-25. [DOI:10.5455/medscience.2013.02.8100]

[11] Capizzi M, Leto G, Petrone A, Zampetti S, Papa RE, Osimani M, et al. Wrist circumference is a clinical marker of insulin resistance in overweight and obese children and adolescents.
Circulation. 2011; 123(16):1757-62. [DOI:10.1161/CIRCULATIONAHA.110.012898] [PMID]

[12] Tibana RA, Teixeira TG, Farias DL, Silva AD, Madrid B, Vieira A, et al. Relation of neck circumference and relative muscle strength and cardiovascular risk factors in sedentary women. Einstein (Sao Paulo). 2012; 10(3):329-34. [DOI:10.1590/S1679-45082012000300013]

[13] Ben-Noun LL, Laor A. Relationship between changes in neck circumference and cardiovascular risk factors. Exp Clin Cardiol. 2006; 11(1):14-20.

[14] Ben-Noun LL, Laor A. Relationship of neck circumference to cardiovascular risk factors. Obes Res. 2003; 11(2):226-31. [DOI:10.1038/oby.2003.35] [PMID]

[15] Amini A, Soltanian N, Iraj B, Askari G, Ebneyamin S, Ghias $\mathrm{M}$, et al. Association of wrist circumference with cardio metabolic risk factors. J Pak Med Assoc. 2012; 62(3 Suppl 2):S34-6.

[16] Pols MA, Peeters PH, Bueno-de-Mesquita HB, Ocke MC, Wentink CA, Kemper HC, Collette HJ. Validity and repeatability of a modified Baecke questionnaire on physical activity. Inter J Epidemiol. 1995; 24(2):381-8. [DOI:10.1093/ ije/24.2.381] [PMID]

[17] Ben-Noun LL, Laor A. Relationship between changes in neck circumference and changes in blood pressure. Am J Hypertens. 2004; $17(5$ Pt 1):409-14. [DOI:10.1016/j.amjhyper.2004.02.005] [PMID]

[18] Bergmeyer HU. Methods of enzymatic analysis: Amsterdam, Netherlands: Elsevier; 2012.

[19] Rodriguez CJ, Daviglus ML, Swett K, González HM, Gallo LC, Wassertheil-Smoller S, et al. Dyslipidemia patterns among Hispanics/Latinos of diverse background in the United States. Am J Med. 2014; 127(12):1186-94. [DOI:10.1016/j. amjmed.2014.07.026] [PMID] [PMCID]

[20] Samson MM, Meeuwsen I, Crowe A, Dessens J, Duursma SA Verhaar H. Relationships between physical performance measures, age, height and body weight in healthy adults. Age Ageing. 2000; 29(3):235-42. [DOI:10.1093/ageing/29.3.235] [PMID]

[21] Lernmark A. type 1 (insulin - dependent) diabetes mellitus: Etiology, Pathogenesis and natural history. In: De Groot LJ, Jamesson JL, editors. Endocrinology. Philadelphia: WB Saunders; 2001.

[22] Androutsos O, Grammatikaki E, Moschonis G, RomaGiannikou E, Chrousos GP, Manios Y, et al. Neck circumference: A useful screening tool of cardiovascular risk in children. Pediatr Obes 2012; 7(3):187-95. [DOI:10.1111/j.20476310.2012.00052.x] [PMID]

[23] Mohebi R, Mohebi A, Sheikholeslami F, Azizi F, Hadaegh F. Wrist circumference as a novel predictor of hypertension and cardiovascular disease: Results of a decade follow up in a West Asian cohort. J Am Soc Hypertens. 2014; 8(11):800-7. [DOI:10.1016/j.jash.2014.08.010] [PMID]

[24] Navaii L, Mehrabi Y, Azizi F. An epidemiologic study of hyperlipidemia, obesity, and hypertension in Tehran villages. Irani J Endocrinol Metab. 2000; 2(4):253-62.

[25] Patil SP, Sukumaran S, Bhate A, Mukherji A, Chandrakar $\mathrm{S}$. Correlation of Blood sugar with waist circumference and body mass index in an Indian population. Glob J Pharmacol. 2012; 6(1):8-11. 